
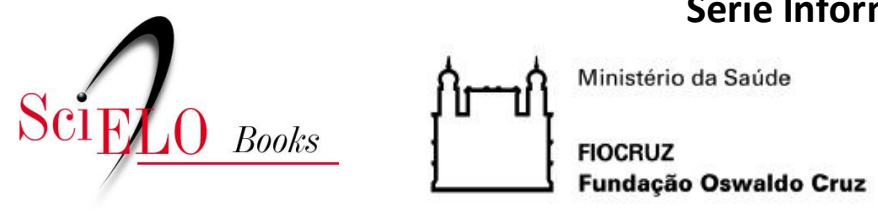

OBSERVATÓRIO COVID-19

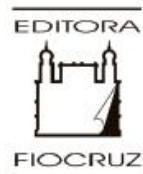

Parte I - A doença e suas circunstâncias

\title{
3. Desenvolvimento e pandemia transformação estrutural para além de um novo normal
}

\author{
Carlos Augusto Grabois Gadelha
}

\section{SciELO Books / SciELO Livros / SciELO Libros}

GADELHA, C.A.G. Desenvolvimento e pandemia transformação estrutural para além de um novo normal. In: BUSS, P.M., and FONSECA, L.E. eds. Diplomacia da saúde e Covid-19: reflexões a meio caminho [online]. Rio de Janeiro: Observatório Covid 19 Fiocruz; Editora FIOCRUZ, 2020, pp. 41-50. Informação para ação na Covid-19 series. ISBN: 978-65-5708-029-0. https://doi.org/10.7476/9786557080290.0004.

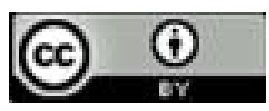

All the contents of this work, except where otherwise noted, is licensed under a Creative Commons Attribution $\underline{4.0 \text { International license. }}$

Todo o conteúdo deste trabalho, exceto quando houver ressalva, é publicado sob a licença Creative Commons Atribição 4.0.

Todo el contenido de esta obra, excepto donde se indique lo contrario, está bajo licencia de la licencia Creative Commons Reconocimento 4.0. 


\section{3 \\ Desenvolvimento e Pandemia transformação estrutural para além de um novo normal}

Carlos Augusto Grabois Gadelha

D iante da pandemia do novo coronavírus, emerge a percepção sobre os grandes problemas no sistema nacional e global em que vivemos. Muitos economistas entusiastas dos mecanismos autorreguladores do mercado passaram, diante do impasse, a redescobrir Keynes e o papel do Estado. Todavia, como quem espera, à espreita, o perigo e o medo passarem, há, subliminarmente, a perspectiva de que tudo voltará a ser como antes, ainda que sob a marca do romance de Lampedusa de que algo deve mudar para que tudo continue como está e que o mundo do mercado e das finanças permaneça sem freios e sem direcionamento público e continue livre para a predominância da lógica financeira, especulativa e assimétrica do capital, ainda que sob o manto de um "novo normal".

O novo e conservador normal proposto reforçará a natureza da sociedade capitalista em seu momento "livre e turbinado", agravando a desigualdade estrutural em todas suas manifestações, ainda que, para os menos agressivos no exercício dos "plenos poderes", possa haver medidas paliativas para manter níveis mínimos de controle e calma social, com ações benevolentes e compensatórias que deem estabilidade para que o escorpião da metáfora siga agindo de acordo com sua natureza em todas as esferas da vida. Domesticada pelas novidades remotas, pela ilusão dos empreendedores livres e autônomos e por mínimos assistenciais e ambientais que permitiriam conter a revolta e manter a alienação, perpetua-se uma classe de sub-humanos excluídos inexoravelmente da sociedade do conhecimento em sua fase 4.0.

Em contraposição a um subterfúgio conservador e retrógrado aparentemente predominante nos discursos comumente disponíveis (retrógrado sim, pois mesmo na crise pandêmica o ideal do futuro desta forma sutil de dominação retorna ao período 
anterior a 1945), alerto para o que considero o papel mais nobre do pensamento e de uma ciência social moral como deveria ser a economia. Após a crise de 2008, quando, assim como hoje, muitos iludidos falavam da retomada do pensamento keynesiano, do papel do Estado na regulação do mercado e da importância da esfera coletiva, tudo piorou. Mader, Zwan e Mertens (2020) destacaram que o "novo normal” que surgiu pós-2008 foi um mundo de crescente financeirização, austeridade, precarização de empregos e explosão da desigualdade.

Reforço a urgência da discussão com a sociedade para que não se naturalize a saída da crise pandêmica e para que tudo não volte a ser como antes, em bases piores, pois o mundo e o capital estarão mais concentrados e desiguais. Corroborando com o que Mazucatto (Rodríguez, 2020) afirma, o capitalismo pode ser orientado para um "futuro inovador e sustentável que funcione para todos nós”. É imprescindível que uma grande transformação comece a se plasmar a partir das forças sociais e políticas atuantes no mundo e no Brasil com base em uma visão e ação generosas e cooperativas em âmbito nacional e global para compatibilizar a ordem capitalista com a vida, com a dignidade humana, com o ser coletivo associado aos sistemas universais de proteção social e com o direito à democracia, ao conhecimento científico e tecnológico e ao desenvolvimento.

No campo da saúde, essa percepção passa por fortalecer, simultaneamente, a conquista da construção do Sistema único de Saúde (SUS) - viabilizando o acesso universal, equânime e integral - e das bases de conhecimento, tecnológicas e produtivas que the dão sustentação, como elementos fundamentais para que as iniquidades, assimetrias, a dependência e a vulnerabilidade social e econômica, reveladas pela pandemia, sejam minimizadas. A doença atinge toda a população, mas seus efeitos se mostram extremamente desiguais e socialmente perversos quando analisado o número de óbitos entre diferentes grupos e classes sociais.

A ciência brasileira, mais do que nunca, está mostrando seu valor para a sociedade em um momento crucial como o da pandemia, como revelado pela chance única que tem o Brasil de participar do esforço global de inovação para o acesso universal à vacina para a Covid-19. A densidade científica e tecnológica envolvida no processo de desenvolvimento e absorção de tecnologia para uma vacina é imensa, e estamos no jogo porque nunca saímos dele. O Programa Nacional de Imunizações, criado em 197 I, é o exemplo mais avançado da convergência do direito universal à saúde com a construção de bases produtivas e tecnológicas locais, e precisa ser generalizado para todo o sistema de produção e inovação em saúde, o Complexo Econômico-Industrial da Saúde (Ceis).

É essa articulação da dimensão social com a econômica, científica e tecnológica do desenvolvimento que permitirá ao Brasil voltar a ter protagonismo para sair de um 
normal conservador e excludente e entrar em um processo de transformação que torne claro que os direitos sociais e a saúde, ao contrário de fatores impeditivos, são motores para a superação da crise atual, aliando equidade, direitos, desenvolvimento científico e tecnológico e a produção nacional qualificada, de forma a superar os falsos dilemas entre sociedade e economia.

\section{SAÚDE E DESENVOLVIMENTO EM UMA PERSPECTIVA ESTRUTURAL}

A pandemia do novo coronavírus confirmou, de modo contundente, a perspectiva adotada de que as dimensões econômicas e sociais do desenvolvimento são incontornavelmente vinculadas. A visão para o contexto atual foi desenvolvida no texto "O Complexo Econômico-Industrial da Saúde no Brasil hoje" elaborado para a Fundação Friedrich Ebert (FES Brasil), parte integrante do especial "Crise da Covid- 19: de que políticas públicas o Brasil precisa?", em que foi reforçado o conceito de Complexo Econômico-Industrial da Saúde (Ceis) desenvolvido no início dos anos 2000 (Gadelha, 2020a). Trata-se da relação indissociável entre saúde e desenvolvimento, segundo perspectiva endógena que considera a saúde e o sistema de produção e de inovação relacionado como parte de um padrão de desenvolvimento, e não apenas como um fator acessório, funcional e exógeno à dinâmica do capital.

Nesse artigo, é evidenciada a visão restrita da relação saúde-desenvolvimento, adotada inclusive pela Organização Mundial da Saúde (OMS) há cerca de duas décadas, em forte interação com o Banco Mundial e o Fundo Monetário Internacional (FMI). Essa visão foi consolidada e intensamente difundida no relatório clássico de $200 \mathrm{I}$ sobre a relação entre economia e saúde, Macroeconomics and Health: investing in health for economic development, em que essa concepção, a despeito de, acertadamente, considerar a saúde como um direito humano essencial, acaba, do ponto de vista econômico, reduzindo essa relação ao fornecimento de capital humano. É o que implicitamente aparece na "ajuda" que os países desenvolvidos deveriam oferecer aos países pobres (com grande destaque para a África) para que o enfrentamento e a redução da incidência de doenças como Aids, malária e tuberculose (entre muitas outras doenças transmissíveis) permitissem elevar a produtividade do trabalho e o investimento privado, limitados por uma "infestação" sanitária nos países e regiões pobres.

No artigo, a vertente ortodoxa "esclarecida" do pensamento sobre o elo entre saúde e desenvolvimento é também considerada com base nos trabalhos liderados por importantes pensadores liberais, com destaque para Amartya Sen, que trata a saúde como fator essencial da liberdade de escolha, seguindo o individualismo metodológico que associa o desenvolvimento à liberdade dos indivíduos em sua singularidade. A saúde aparece, mais 
uma vez, como fator exógeno que contribui ou não para o exercício da liberdade individual. A citada concepção leva à conclusão de que "pessoas saudáveis são mais livres para escolher". São reducionismos que não consideram as mazelas sociais e econômicas que estão por trás da geração estrutural de desigualdade em todos os seus níveis.

Em todas essas visões fica omitida a reprodução endógena e dialética da dinâmica capitalista no interior da saúde, que envolve tanto o desenvolvimento das forças produtivas, do investimento, do emprego e da inovação quanto a tendência, inerente ao nosso sistema econômico, de geração de assimetrias e desigualdades nos níveis sociais, territoriais e nacionais, em um processo de clara globalização movida pela inovação em todas suas dimensões (inclusive a financeira) e pela simultânea exclusão.

A realidade concreta da saúde e das necessidades sociais, como revelado de modo devastador na pandemia do novo coronavírus, impõe a necessidade de uma visão integrada. Ficou evidente que as dificuldades na importação de produtos essenciais como ventiladores pulmonares, materiais médicos, insumos dos testes para diagnóstico e as complexas negociações para a transferência de tecnologia em vacinas e outros produtos são questões simultaneamente econômicas e sociais. A separação dessas dimensões é fruto de um olhar analítico fragmentado e reducionista, enraizado na economia, mas também em outras ciências sociais e nas políticas públicas, afastandose dos contextos históricos e temporais específicos nos quais essas dimensões estão articuladas sistemicamente. Temos que conformar um novo padrão de política pública que seja, ao mesmo tempo, sistêmico e comprometido com as demandas de nossa sociedade para garantir o bem-estar.

A abordagem adotada procura olhar a saúde como componente essencial da dinâmica econômica que se reproduz em um espaço específico e de alta importância estratégica. Se a dinâmica global atual gera novas frentes de expansão e de inovação, estas se expressam também no campo da saúde como um dos mais dinâmicos no contexto da quarta revolução tecnológica. Se, ao mesmo tempo, gera assimetrias e exclusão, estas também se reproduzem no campo da saúde. Como desdobramento, e incorporando uma visão de economia política, há necessidade de considerar os espaços de formulação e implementação de políticas públicas pelos Estados nacionais - daí o diálogo analítico e político dessa concepção com as linhas de pesquisa e de políticas públicas que abordam os sistemas nacionais de inovação e os sistemas nacionais de saúde e de bem-estar. Isso envolve, inexoravelmente, a interação desses sistemas com os projetos nacionais de desenvolvimento que, como mencionado, podem, dependendo da escolha política das sociedades, se inserir em processos globais pautados pela solidariedade e pelo direito à vida dos diferentes povos e regiões. 


\section{O COMPLEXO ECONÔMICO-INDUSTRIAL DA SAÚDE (CEIS) E A VULNERABILIDADE DOS SISTEMAS UNIVERSAIS}

Em "Covid-19: a necessidade de retomada de uma agenda estrutural de desenvolvimento", texto original escrito para o Jornal dos Economistas do Conselho Regional de Economia do Rio de Janeiro, defendo, seguindo a aposta teórica da concepção do Ceis, que a pandemia da Covid-19 evidenciou, de modo dramático, que era necessário compreender a base econômica, produtiva e tecnológica da saúde como um sistema interdependente, e não como um conjunto fragmentado de setores (Gadelha, 2020b). E que isso permitirá sair das amarras cognitivas das políticas industriais clássicas do pós-guerra, sempre focadas em segmentos produtivos particulares, facilitando a captura por interesses também particulares.

Tal compreensão envolvia também uma ruptura das barreiras cognitivas e políticas entre as dimensões econômica e social do desenvolvimento. Essas duas dimensões passavam a ser endogeneizadas em certo padrão de desenvolvimento que envolve, a um só tempo e de modo indissociável, os direitos sociais, a equidade e as características da base produtiva e de inovação, sem cair em nenhum reducionismo de determinação de uma instância sobre a outra.

Na perspectiva do Ceis, estamos vulneráveis para enfrentar o coronavírus, como pedintes em um mercado internacional permeado por interesses mercantilistas, em uma abordagem de economia política que articula poder econômico, tecnológico e político. No presente, mais de noventa países já adotam práticas protecionistas com imposição de barreiras e impedimentos ao acesso aos seus produtos, o que é ainda mais grave no âmbito dos países menos desenvolvidos. Nossas importações chegam a quase um orçamento do Ministério da Saúde (podemos estimar em US\$ 20 bilhões se contabilizarmos, além das importações em produtos captadas nas estatísticas de comércio exterior, as advindas de bens intermediários e dos pagamentos por tecnologias, reconhecidamente significativos na área da saúde). Apenas em ventiladores pulmonares a dependência do Brasil quintuplicou em termos reais nos últimos vinte anos, atingindo US $\$ 50$ milhões, segundo dados obtidos mediante metodologia utilizada pelo Grupo de Pesquisa Desenvolvimento, Complexo Econômico-Industrial e Inovação em Saúde (GIS), que coordeno na Fiocruz - ver entrevista concedida à revista Radis sob o título "A Covid escancarou problemas estruturais" (Morosini, 2020).

Ainda no texto, cito a imagem mencionada no artigo com o ex-ministro José Gomes Temporão, "Tecnologia em saúde: Brasil não pode ficar de joelhos”, no qual argumento que o SUS, como maior sistema universal do mundo, está assentado em "pés de barro" 
no enfrentamento da crise atual. Isso em razão da fragilidade da capacidade produtiva e tecnológica local, tanto para ofertar produtos essenciais no país quanto para se articular de modo soberano com empresas e países mais desenvolvidos, envolvendo acordos de transferência de tecnologia e também relações comerciais virtuosas e complementares para atender às necessidades sociais (Temporão $\&$ Gadelha, 2020).

No presente, estamos reféns de uma competição monopólica desleal com práticas que afastam o mundo dos objetivos meritórios de um desenvolvimento global sustentável. As situações econômica e social são dramáticas e completamente indissociáveis.

A pandemia atual do coronavírus revela e confirma a hipótese analítica e metodológica do Ceis. Observamos sequestro de produtos médicos; cancelamento de contratos de ventiladores pulmonares pela existência de "propostas" melhores de países desenvolvidos; falta de acesso a insumos para testes de diagnóstico; extrema fragilidade dos programas de atenção primária em saúde, que foram atingidos por políticas econômicas e sociais restritivas do poder público (seguindo, muitas vezes, a concepção de economistas defensores da austeridade sem limites, em prejuízo da visão moral que marcou a economia política em seu nascimento); unidades de terapia intensiva (UTIs) públicas operando acima do limite de sua capacidade de atendimento, sem garantia de acesso aos excluídos; e diferenças e desigualdades entre pessoas e territórios dentro de nosso país, que geram taxas de letalidade por infecção de coronavírus de mais de dez vezes de diferença entre pessoas que deveriam ter os mesmos direitos. As dimensões econômicas e sociais do desenvolvimento são inevitavelmente vinculadas, de forma que se constitui, ao mesmo tempo, em um erro e em uma falta de visão a oposição nefasta e perversa entre a economia e a saúde.

\section{DE UMA NOVA VISÃO A UM NOVO PROJETO DE TRANSFORMAÇÕES ESTRUTURAIS}

As reflexões apresentadas, seguindo os artigos e entrevistas citados, indicam que para avançar é urgente apontar caminhos para o futuro, pois a realidade em seu curso natural será dramática, não apenas para essa pandemia, mas também para as futuras epidemias e pandemias e para os problemas de saúde que afetam o Brasil, desde o campo das doenças transmissíveis até o das doenças crônicas como câncer e doenças do sistema circulatório, assim como as referentes à saúde mental como a depressão, a tristeza e a solidão, tão marcantes nestes tempos difíceis. A crise e a vulnerabilidade serão agravadas se não pensarmos e agirmos de forma diferente como sociedade nacional e global. 
Ao contrário das políticas industriais e de desenvolvimento produtivo tradicionais, com a marca setorial e muitas vezes capturadas por interesses particulares, temos que aprender um novo padrão de política pública que, ao mesmo tempo, seja sistêmico e comprometido com as demandas de nossa sociedade para garantir o bem-estar. Sistêmico porque o foco nas necessidades, como na saúde, envolve a articulação entre diferentes indústrias (farmacêutica e biotecnológica, de equipamentos e materiais médicos) e destas com os serviços de saúde (o elo final do sistema produtivo da saúde, onde todos os produtos industriais são utilizados, a exemplo do uso dos ventiladores nas UTIs). Comprometidos com as demandas da sociedade porque, contrariamente a um desenvolvimentismo vulgar, não cabe apenas apoiar setores produtivos se estes não estiverem vinculados às necessidades sociais. Não apenas as políticas setoriais, mas também as ditas como orientadas por missões, precisam se inserir em realidades histórico-concretas das necessidades das pessoas que, afinal, financiam o Estado e geram a riqueza de nosso país.

É para a sociedade real brasileira e global que as políticas de desenvolvimento produtivo e de ciência, tecnologia e inovação devem estar voltadas. A perspectiva apresentada propõe uma abordagem passível de ser generalizada para viabilizar um padrão de desenvolvimento norteado pela equidade, pelo bem-estar e pelo dinamismo econômico e tecnológico, se espelhando no Ceis como um dos sistemas produtivos mais importantes e estratégicos do mundo, e pela soberania para implementar políticas sociais para que possamos atender às necessidades de nossa sociedade e não deixar as pessoas vulneráveis para trás pela irracionalidade de uma visão de desenvolvimento míope que opõe os direitos sociais à economia. Os direitos sociais e o direito à vida não apenas cabem no Produto Interno Bruto (PIB), mas são parte essencial da solução, constituindo uma alavanca para a superação estrutural da crise.

A emergência desta pandemia no início do ano evidenciou que seu enfrentamento requeria forte articulação sistêmica, envolvendo: capacidade de inteligência no tratamento e análise dos dados epidemiológicos; disponibilidade em larga escala de produção industrial de testes de diagnóstico moleculares e de seu processamento nos serviços de saúde; produção de equipamentos de proteção individual (EPIs) para o uso por profissionais nos serviços de saúde; existência de máscaras, luvas e materiais de higiene e limpeza no contexto de uma população extremamente vulnerável e sem recursos básicos de água e esgoto; estruturação de uma rede de serviços de atenção básica (decisivos para o cuidado com a saúde e para o diagnóstico rápido e encaminhamento dos pacientes) e de UTIs; capacidade tecnológica e industrial para a produção em escala das futuras vacinas, medicamentos e serviços que utilizem grandes bases de dados e inteligência artificial; 
e enorme aporte das ciências sociais na questão crucial da sociedade que queremos, incluindo a (re)construção de estratégias e meios para viabilizar e atualizar os sistemas de proteção social.

Basta que uma peça do sistema não funcione para fazer ruir toda uma estratégia de saúde e toda capacidade nacional de resposta. A falta de ventiladores, a inexistência de UTIs e de profissionais para sua operação, uma lacuna na organização da atenção básica aberta pela falta de equipes de saúde da família para uma atuação são, todas elas, falhas capazes de desestabilizar o sistema. Os ventiladores apareceram como a ponta de um iceberg que revelou, na fase final da linha do cuidado, a necessidade de articulação sistêmica e as fragilidades dos países como o Brasil em situações de emergência.

A fragilidade e a dependência externa do Complexo Econômico-Industrial da Saúde nacional se impõem como um grande problema de saúde pública. Se faltam EPIs, nossos profissionais da saúde adoecem e morrem de modo triste e desumano. Se faltam ventiladores, a inaceitável segmentação entre ricos e pobres aparece, de modo que uns têm direito à vida ao passo que outros são condenados à morte em uma triste escolha silenciosa de nosso país desigual e excludente. Se não existem sistemas de água e esgoto para todos e se a atenção básica não é estruturada em todo o território, assistimos, por exemplo, a uma das faces mais perversas de nossa desigualdade, na qual a alta letalidade no bairro da Maré, no Rio de Janeiro, chega a ser mais de dez vezes superior à letalidade de bairros da zona sul do mesmo estado.

O direito à vida não tem sido respeitado por falta de capacidade nacional produtiva e tecnológica e por uma visão míope que leva a fragilizar o SUS porque, irresponsavelmente, se advoga que os direitos sociais não cabem no PIB. A saúde é claramente uma frente essencial de desenvolvimento que gera $9 \%$ do produto, 14 milhões de empregos diretos e indiretos e 30\% da capacidade nacional de pesquisa, além de ser a mais promissora porta de entrada na $4^{a}$ Revolução Industrial. Este setor lidera, no mundo, as novas tecnologias digitais, envolvendo inteligência artificial, o uso e tratamento de grandes bases de dados, as tecnologias de impressão 3D, os conhecimentos em genética (incluindo a edição genética) e sua fusão com o mundo digital, entre muitas outras frentes que respondem pelas profundas transformações em curso.

A perspectiva sistêmica e endógena apresentada não reduz a necessidade de atuação do Estado no desenvolvimento do sistema produtivo e de inovação, mas acentua os requerimentos articulados de intervenção e a necessidade de conexão com a sociedade. Os economistas devem lembrar os ensinamentos de Celso Furtado de que não há desenvolvimento quando as necessidades da população não são atendidas. É necessário 
pensar um novo Estado vinculado às demandas da sociedade, inserido, conectado, transparente e blindado das capturas setoriais.

Este momento dramático do contexto brasileiro impõe a necessidade de diálogo, de generosidade, de respeito mútuo e de ação conjunta para defender as pessoas, a economia nacional e uma sociedade que seja civilizada, na qual a saúde, a equidade, o meio ambiente, a ciência, tecnologia $E$ inovação (CTEl) e o dinamismo econômico sejam objetivos compatíveis e favoreçam uma ação global pautada pela solidariedade. Em vez de um "novo normal" que reproduza nossa desigualdade e as assimetrias globais, podemos construir uma agenda mínima de transformações estruturais que supere as tendências em curso de acirramento da exclusão e da progressiva barbárie social para que possamos construir um país e uma sociedade melhores, comprometidos com as pessoas que aqui vivem e que são os responsáveis pela riqueza aqui gerada.

Não se pode tirar da partilha do PIB justamente aqueles que geram a riqueza na qual todos estão assentados. É uma questão ética e humana e, ao mesmo tempo, uma saída para a crise estrutural econômica e civilizatória que enfrentamos ao longo deste século e que precisa ser revertida. Depende de nossas ações e de nossa capacidade de diálogo e de construir, em conjunto, um novo projeto e uma nova utopia transformadora que associe mudança na estrutura social, mudança na estrutura econômica, mudança na participação política e democrática, mudança na esfera da vida, mudança na sociabilidade, mudança na forma de nos relacionarmos com o outro e com a natureza. O futuro é incerto. A trajetória "natural" será o abismo para todos ou a barbárie social. Podemos domar o escorpião na construção de uma sociedade melhor. Já foi possível no passado. Será possível no futuro? Como diria o filósofo, seremos o produto de nossas escolhas!

\section{AGRADECIMENTO}

Agradeço a importante colaboração da equipe da Coordenação das Ações de Prospecção da Fiocruz e, especialmente, de Karla Bernardo Mattoso Montenegro, que, com seu apoio, viabilizou a realização deste trabalho. 


\section{REFERÊNCIAS}

GADELHA, C. G. O Complexo Econômico-Industrial da Saúde no Brasil hoje. FES BR Friedrich-EbertStiftung Brasil - FES BR, São Paulo, 12 maio 2020a, p. I. Disponível em: < https://www.fes-brasil.org/ detalhe/o-complexo-economico-industrial-da-saude-no-brasil-hoje/>. Acesso em: 18 set. 2020.

GADELHA, C. G. Pandemia Covid-19: a necessidade de retomada de uma agenda estrutural de desenvolvimento. Jornal dos Economistas - JE, Rio de Janeiro, 27 jun. 2020b, p. 10-12. Disponível em: $<$ http://www.corecon-rj.org.br/anexos/6 I 9CA0C544A7E7BB76C67A9284958 I 82.pdf>. Acesso em: I 8 set. $2020>$. Disponível em: 18 set. 2020.

MADER, P.; ZWAN, N. \& MERTENS, D. 9 ways coronavirus could transform capitalism. Tribune, Dagenham, 2 jun. 2020. Disponível em: < https://tribunemag.co.uk/2020/06/9-ways-coronavirus-couldtransform-capitalism>. Acesso em: 18 set. 2020.

MOROSINI, L. A Covid escancarou problemas estruturais. Radis, Rio de Janeiro, I 3 jul. 2020. Disponível em: <https://radis.ensp.fiocruz.br/index.php/home/entrevista/a-covid-escancarouproblemas-estruturais $>$. Acesso em: 18 set. 2020.

RODRÍGUEZ, M. A economista que defende uma mudança radical no capitalismo para o mundo pós pandemia. BBC News Brasil, São Paulo, 8 ago. 2020. Disponível em: <www.bbc.com/portuguese/ internacional-5368643 I >. Acesso em: I 8 set. 2020.

TEMPORÃO, J. G. E GADELHA, C. G. Tecnologia em saúde: Brasil não pode ficar de joelhos. Folha de S.Paulo - UOL, São Paulo, 19 abr. 2020, p. A3. Disponível em: <https://wwwl.folha.uol.com.br/ opiniao/2020/04/tecnologia-em-saude-brasil-nao-pode-ficar-de-joelhos.shtml>. Acesso em: 18 set. 2020 . 